\title{
Extracorporeal shock wave lithotripsy of bile duct stones: a single institution experience
}

\author{
E Lindström, K Borch, E P Kullman, H G Tiselius, I Ihse*
}

\begin{abstract}
Extracorporeal shock wave lithotripsy treatment with Dornier HM3 or MPL 9000 machines was applied in 37 patients with problematic bile duct stones. General anaesthesia was not required. After one extracorporeal shock wave lithotripsy session 14/37 patients (38\%) were spontaneously stone free, and additional endoscopic extraction (eight of 37) and retreatments with extracorporeal shock wave lithotripsy (seven cases) increased the stone free rate to $29 / 37(78 \%)$. In three patients with intrahepatic stones, the bile ducts could not be evaluated decisively at cholangiography and ultrasonography, but they were all symptom free at 15 to 38 months follow up. If these three patients are added to the radiologically stone free patients, the overall clinical success rate was $32 / 37(86 \%)$. There were no serious complications, hospital admissions, or $\mathbf{3 0}$ day mortality as a result of extracorporeal shock wave lithotripsy or endoscopic procedures. It is concluded that extracorporeal shock wave lithotripsy is a valuable adjunct to the nonsurgical treatment of bile duct stones.

(Gut 1992; 33: 1416-1420)
\end{abstract}

Since 1982 extracorporeal shock wave lithotripsy is an established method for fragmentation of renal and ureteric stones and more than 200000 patients have been treated. ${ }^{12}$ At our hospital extracorporeal shock wave lithotripsy of nephro ureteric stones has been given at 3300 occasions since $1985 .^{3}$ In 1986 extracorporeal shock wave lithotripsy was extended by Sauerbruch et al to include treatment of gall bladder stones, bile duct stones and pancreatic duct stones. ${ }^{45}$ While the experience with treating gall bladder stones advanced rapidly, ${ }^{6-9}$ the treatment of bile duct stones has progressed more cautiously. Most reports either describe a limited experience with a few patients or represent multi institutional series composed of few patients from each hospital. ${ }^{50-12}$ The need for general anaesthesia in these series has been surprisingly high. In 1989

TABLE I Patient characteristics

\begin{tabular}{llccc}
\hline Stone location & $\begin{array}{l}\text { Patients } \\
(n)\end{array}$ & $M / F^{\star}$ & $\begin{array}{l}\text { Age } \\
(y r)\end{array}$ & $\begin{array}{l}\text { Referred from } \\
\text { other hospitals }\end{array}$ \\
\hline Common bile duct & 28 & $15 / 13$ & $\begin{array}{c}82 \\
(47-96)\end{array}$ & $17 / 28$ \\
$\begin{array}{l}\text { Cholecystectomised } \\
\text { Intrahepatic duct }\end{array}$ & $17 / 25$ & $9 / 6$ & $\begin{array}{c}54 \\
(34 / 74)\end{array}$ & $7 / 9$ \\
$\begin{array}{l}\text { Cholecystectomised } \\
\text { Total }\end{array}$ & $9 / 9$ & $18 / 19$ & 68 & $24 / 37$ \\
\hline
\end{tabular}

^M/F designates male/female ratio. Age is expressed as mean and range (within brackets).

we started to treat bile duct stones with the HM3 lithotriptor and in 1988 the MPL lithotriptor was installed and since then we have treated 150 patients with gall bladder stones.

The aim of this paper is to describe our single institution experience with extracorporeal shock wave lithotripsy for problematic bile duct stones in the first 37 patients.

\section{Methods}

\section{PATIENTS}

The series initially comprised 41 patients with problematic bile duct stones, 27 of whom were referred from other hospitals. Three patients could not be positioned for focusing of the stone(s) because of lung tissue in the shock wave path in two, and severe kyphosis in one. In another patient the extracorporeal shock wave lithotripsy treatment had to be discontinued because of severe cardiac arythmia (sinustachycardia). These patients were not further evaluated. Among the remaining 37 patients the bile duct stones were intrahepatic in nine. Previous cholecystectomy had been performed in 24 of the 37 patients. The mean age of the 28 patients ( 15 men and 13 women) with common duct stones was 82 (range 47-96) years. The mean age of the nine patients (three men and six women) with intrahepatic stones 54 (range 34-74) years. Extracorporeal shock wave lithotripsy treatment was chosen either because the patients were old and frail with a high surgical risk and/or because endoscopic treatment had been unsuccessful or unfeasible. The main indications for treatment were cholangitis (18 cases), retained stones (11 cases), jaundice (five cases) and biliary colic (three cases). The median diameter of the stones was 19 (range 6-40) $\mathrm{mm}$ and $18 / 37$ patients had more than one stone (Tables I, II). No stone was radiologically calcified on plain abdominal ray examination.

Before extracorporeal shock wave lithotripsy, endoscopic sphincterotomy ${ }^{13}$ had been performed in all but four patients. Of the latter, three had a hepaticojejunostomy and one a surgical sphincterotomy (Table III). Endoscopic stone removal had failed in the 34 patients and the presumed risk of extracorporeal shock wave lithotripsy was considered as less than that of surgery. Nasobiliary drainage was established in 26 patients, a surgical T-tube in six, percutaneous transhepatic biliary drainage in four, and percutaneous cholecystostomy in one (Table III).

Extracorporeal shock wave lithotripsy was performed in all but one case using the first generation kidney lithotriptor Dornier HM3 (Dornier Medizintechnik GmbH, Munich, Ger- 
many) with waterbath and radiographic targetting system. In one case, the treatment was done in the Dornier MPL 9000 (Dornier Medizintechnik $\mathrm{GmbH}$, Munich, Germany) with watercushion and ultrasound targetting. Between 750-2110 discharges were delivered at each session with a voltage of $14-21 \mathrm{kV}$. Because a variable number of shock-waves at different levels of generator voltage were used, we used an energy index, which was calculated using the formula: Voltage $(\mathrm{kV}) \times$ number of shock waves $(\mathrm{Nsw}) \times 10^{-3}$ (Table IV). ${ }^{3}$

The preferred treatment position, which was prone in the HM3 lithotriptor, was achieved in 28 sessions of the total of 45 (Table IV).

No patient needed general anaesthesia, but all were given a standard intravenous premedication with $75 \mathrm{mg}$ pethidinhydrochloride and $5 \mathrm{mg}$ diazepam. Additional pethidinhydrochloride $(25-50 \mathrm{mg})$ and/or diazepam $(5-10 \mathrm{mg})$ was required at 32 of the 45 extracorporeal shock

TABLE II Number of stones per patient and size of the largest stone

\begin{tabular}{llll}
\hline & $\begin{array}{l}\text { l stone } \\
(\text { Patients }) \\
(n)\end{array}$ & $\begin{array}{l}>\text { 1 stone } \\
(\text { Patients }) \\
(n)\end{array}$ & $\begin{array}{l}\text { Maximum } \\
\text { stone } \\
\text { diameter } \\
(m m)\end{array}$ \\
\hline $\begin{array}{c}\text { Stone location } \\
\begin{array}{c}(\mathrm{n}=28) \\
\text { Intrahepatic ducts } \\
(\mathrm{n}=9)\end{array}\end{array}$ & 13 & 15 & $22(12-40)$ \\
$\begin{array}{c}\text { Total } \\
(\mathrm{n}=37)\end{array}$ & 19 & 3 & $15(7-24)$ \\
\hline
\end{tabular}

Stone size is given as mean $(\mathrm{mm})$ and range.

TABLE III Preextracorporeal shock wave lithotripsy procedures and biliary drains

\begin{tabular}{lllllc}
\hline Patients & $E S T$ & $S S T$ & T-tube & PTBD & NBD \\
\hline $\begin{array}{l}\text { Common bile duct } \\
(\mathrm{n}=28)\end{array}$ & 27 & 1 & 5 & $2 \dagger$ & 21 \\
$\begin{array}{l}\text { Intrahepatic ducts } \\
(\mathrm{n}=9)^{\star}\end{array}$ & 6 & 0 & 1 & 3 & 6 \\
$\begin{array}{c}\text { Total } \\
(\mathrm{n}=37)\end{array}$ & 33 & 1 & 6 & 5 & 26 \\
\hline
\end{tabular}

EST: endoscopic sphincterotomy; SST: surgical sphincterotomy; PTBD: percutaneous transhepatic biliary drain; NBD: nasobiliary drain.

$\star$ Three patients had hepaticojejunostomy. †One patient had a percutaneous cholecystostomy.

TABLE IV Data on extracorporeal shock wave lithotripsy treatment energy settings (mean and range) and patient positioning

\begin{tabular}{|c|c|c|c|c|c|}
\hline Patients & $\begin{array}{l}\text { Sessions } \\
(n)\end{array}$ & $\begin{array}{l}\text { Voltage } \\
(\mathrm{kV})\end{array}$ & $\begin{array}{l}\text { Shock waves } \\
(n)\end{array}$ & $\begin{array}{l}\text { Energy index } \\
k V x N_{s r} x 10^{-3}\end{array}$ & $\begin{array}{l}\text { Pronel } \\
\text { supine } \\
\text { position }\end{array}$ \\
\hline $\begin{array}{l}\text { CBD } \\
(n=28) \\
\text { IHD } \\
(n=9) \\
(n=37)\end{array}$ & $\begin{array}{r}36 \\
9 \\
45\end{array}$ & $\begin{array}{l}16 \\
(14-21) \\
14 \\
(14-21) \\
16\end{array}$ & $\begin{array}{l}1800 \\
(750-2100) \\
1900 \\
(1800-2110) \\
1800\end{array}$ & $\begin{array}{l}28 \cdot 4 \\
(21 \cdot 7-56 \cdot 7) \\
26 \cdot 2 \\
(24 \cdot 5-31 \cdot 2) \\
27 \cdot 9\end{array}$ & $\begin{array}{c}22 / 13 \\
6 / 3 \\
28 / 16\end{array}$ \\
\hline
\end{tabular}

CBD: common bile duct; IHD: intrahepatic ducts.

TABLE V Outcome of the extracorporeal shock wave lithotripsy treatment

\begin{tabular}{lcccc}
\hline & $\begin{array}{l}\text { ESWL+ } \\
\text { Spontaneous } \\
\text { stone passage }\end{array}$ & $\begin{array}{l}\text { ESWL+ } \\
\text { Endoscopic } \\
\text { extraction }\end{array}$ & $\begin{array}{l}\text { Radiologically } \\
\text { stone free } \\
\text { patients }\end{array}$ & $\begin{array}{l}\text { Clinically } \\
\text { successful } \\
\text { outcome }\end{array}$ \\
\hline $\begin{array}{l}\text { Patients } \\
\text { CBD } \\
(\mathrm{n}=28)\end{array}$ & $9 / 28(32 \%)$ & $14 / 28(50 \%)$ & $23 / 28(82 \%)$ & $23 / 27(82 \%)$ \\
$\begin{array}{l}\text { IHD } \\
(\mathrm{n}=9)\end{array}$ & $5 / 9(56 \%)$ & $1 / 9(11 \%)$ & $6 / 9(67 \%)$ & $9 / 9(100 \%)$ \\
Total & $14 / 37(38 \%)$ & $15 / 37(41 \%)$ & $29 / 37(78 \%)$ & $32 / 37(89 \%)$ \\
\hline
\end{tabular}

CBD: common bile duct; IHD: intrahepatic ducts. wave lithotripsy sessions. In all cases a local skin anesthetic ointment containing lidocain/prilocain (Emla ${ }^{\circledR}$, Astra, Sweden) was applied where the shock waves were planned to enter the body.

\section{Results}

In 21 of the 28 patients with common bile duct stones, fragmentation was achieved at the first extracorporeal shock wave lithotripsy session, while the remaining seven patients required two treatments. None of the nine patients with intrahepatic stones required more than one treatment session. The total number of sessions was 45 and they lasted on average 50 (range 25-65) minutes.

Cholangiographic check up via the T-tube, percutaneous drains or nasobiliary catheters one to three days after extracorporeal shock wave lithotripsy showed spontaneous stone clearance in nine $(32 \%)$ of the 28 patients with common bile duct stones (Table V, Figs 1, 2, 3, 4). After endoscopic intervention an additional seven patients with common duct stones were cleared, making 16/28 (57\%) stone free. Twelve patients were, thus, not initially cleared in spite of adjunctive endoscopy. Seven of these were retreated with extracorporeal shock wave lithotripsy and successfully cleared at the ensuing endoscopic session. Thus, the total number of stone free patients in the common duct group was 23/28 (82\%) (Table V).

None of the nine patients with intrahepatic stones required more than one treatment session. There was spontaneous stone clearance in five $(56 \%)$ of these patients at cholangiographic check up one to three days post extracorporeal shock wave lithotripsy. One patient was cleared by means of transhepatic stone extraction. Another patient was not amenable to radiological check up because of allergic reaction to the contrast medium. The other two patients had undecisive endoscopic cholangiograms because of difficulty in differentiating air in the ducts from small fragments. Ultrasound control in these three patients was undecisive because of the same problem. All three patients, however, have been symptom free with normal liver tests at follow up 15-38 months later. If these are added to the group of evaluable patients, there is $100 \%$ clinical success rate in the intrahepatic group. If these are presumed to be cleared of stones, the overall fraction of successfully treated patients was $32 / 37$ $(89 \%)$ (Table V). The remaining five patients with retained stones at control endoscopic retrograde cholangiography were regarded as failures. These were not retreated because of severe senility with motor unrest making targetting imprecise. Retreatment with extracorporeal shock wave lithotripsy would have required general anaesthesia, which was contraindicated. Four of these five patients received a permanent endoscopic endoprostheses to ensure unimpeded biliary flow. ${ }^{1+}$ The fifth patient refused further treatment.

There were no complications as a result of endoscopic procedures. One patient had a transient uncomplicated attack of angina pectoris immediately after extracorporeal shock wave lithotripsy and six had transient macroscopic 


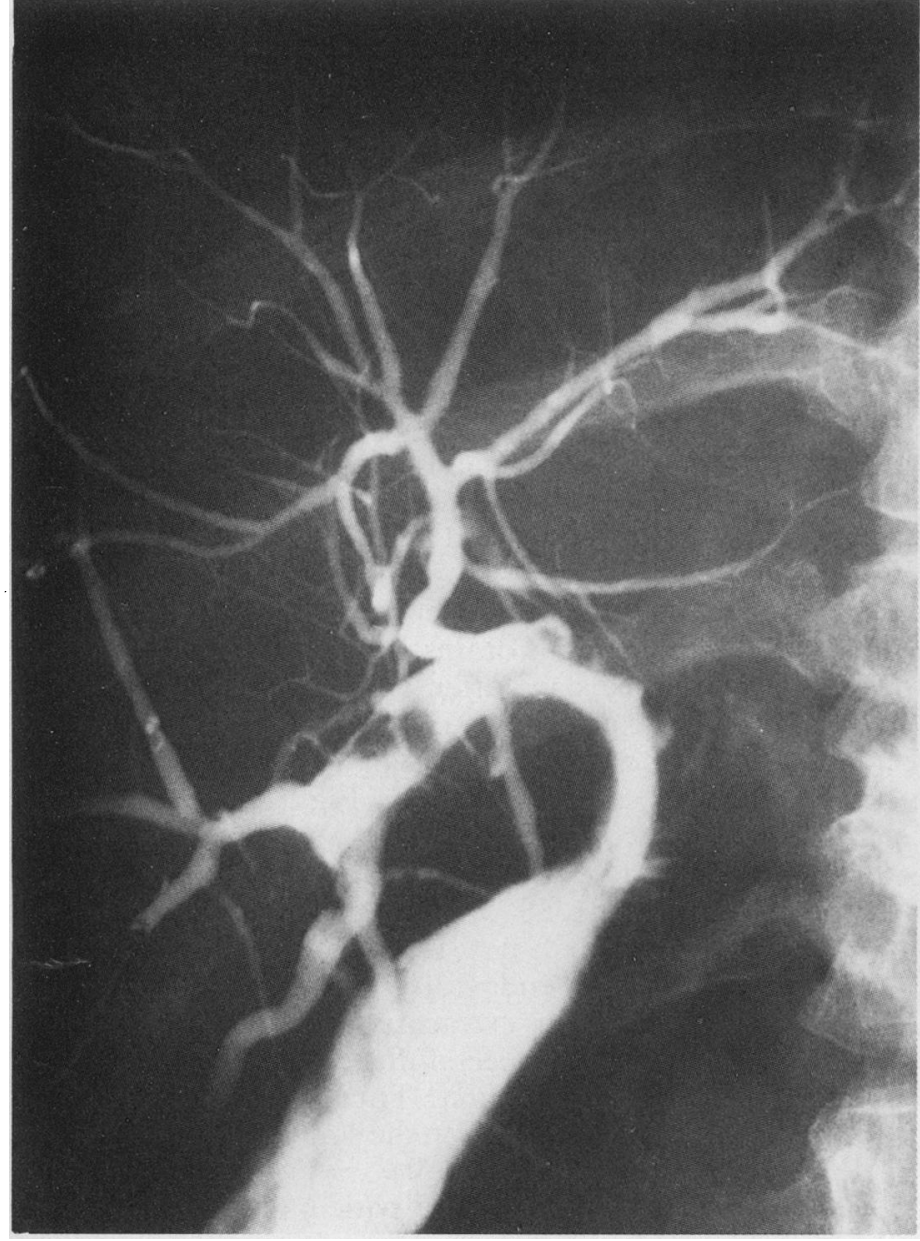

Figure 1: A narrow

hepaticojejunostomy, which was dilated, with balloon catheter through the

percutaneous transhepatic route preceeding

extracorporeal shock wave lithotripsy. The patient has

6-8 mm stones lodged above the stenosis.

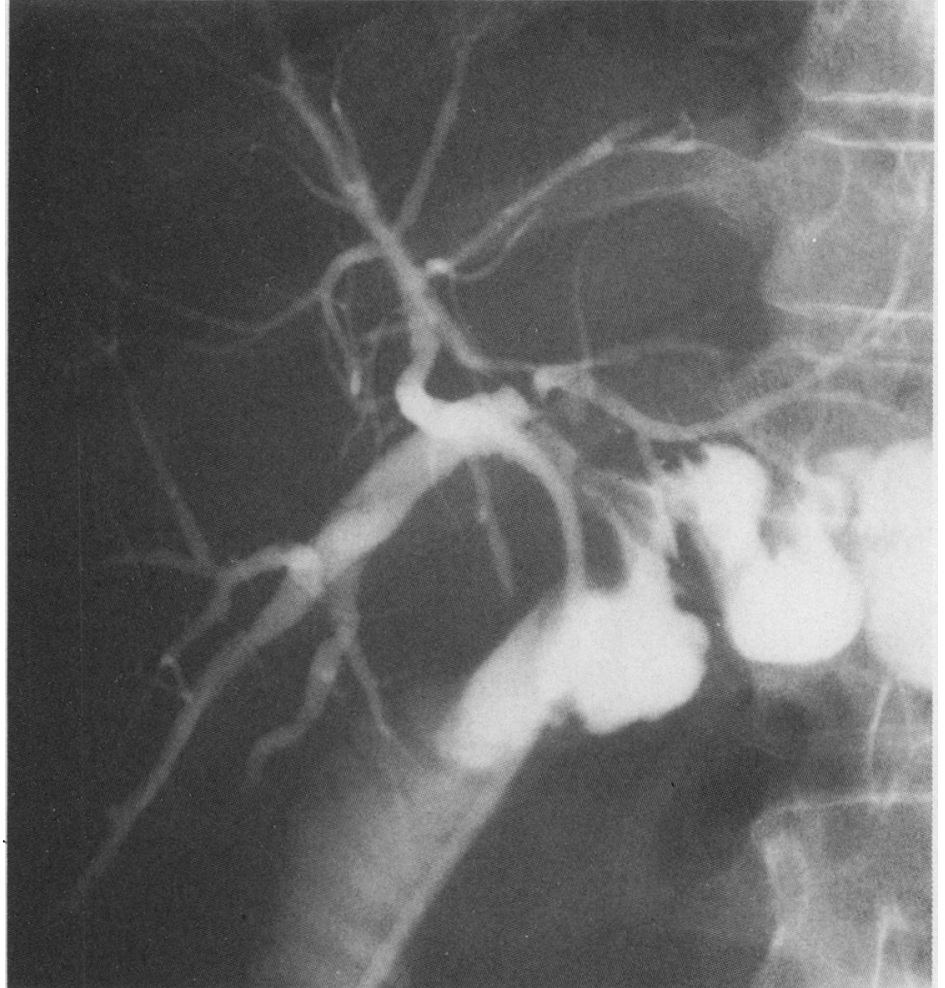

Figure 2: The same patient as in Figure 1. The stones fragmented successfully during extracorporeal shock wave lithotripsy and passed spontaneously to the jejunum.

often old and frail patients is high ${ }^{2021}$ and with intrahepatic stones surgery is not even feasible. The new technology of extracorporeal shock wave lithotripsy first used for nephro ureteric stone ${ }^{1-3}$ and later on for gall bladder stones, ${ }^{45}$ has also proved suitable to reduce the size of bile duct stones. $^{45}$

Our 37 patients were divided into two groups: 28 with extrahepatic bile duct (common duct) stones and nine with intrahepatic stones. The patients with common duct stones were older (mean age 82 years), had a larger average stone size and a greater number of stones than the patients with intrahepatic stones (mean age 54 years). Thus, the former group was the most problematic. The larger the stone volume the more energy was required for fragmentation to a suitable size. Therefore, we had less spontaneous clearance rates $(32 \%)$ and also seven retreatments in the former group, but in the group with intrahepatic stones the spontaneous clearance rate was $56 \%$ and no retreatments were needed. Three patients had a hepatico jejunostomy, two were cleared spontaneously and one was made stone free transhepatically. One patient had rather small stones (5-6 mm) (Figs 1,2$)$, but a tight stoma, which posed problems, illustrating that not only stone size but stone size in relation to outlet passage diameter influences success rates.

The five patients with common duct stones in whom treatment failed were old and suffered from senility and motor unrest. Retreatment session would have required general anaesthesia, which was deemed too high a risk. Four were treated with permanent endoscopic endoprostheses to secure the bile flow. This is a reasonable alternative to failed endoscopic mplications such as bleeding and per tion. Instead of enlarging the sphincterotomy, one might reduce the stone size. Chemical dissolution has been used, but is ineffective, time consuming ${ }^{17}$ and difficult to handle. ${ }^{17}{ }^{18}$ Mechanical lithotripsy using the stone crushing basket frequently fails in large and impacted stones. ${ }^{19}$ Another option is surgery, but the risk in these 

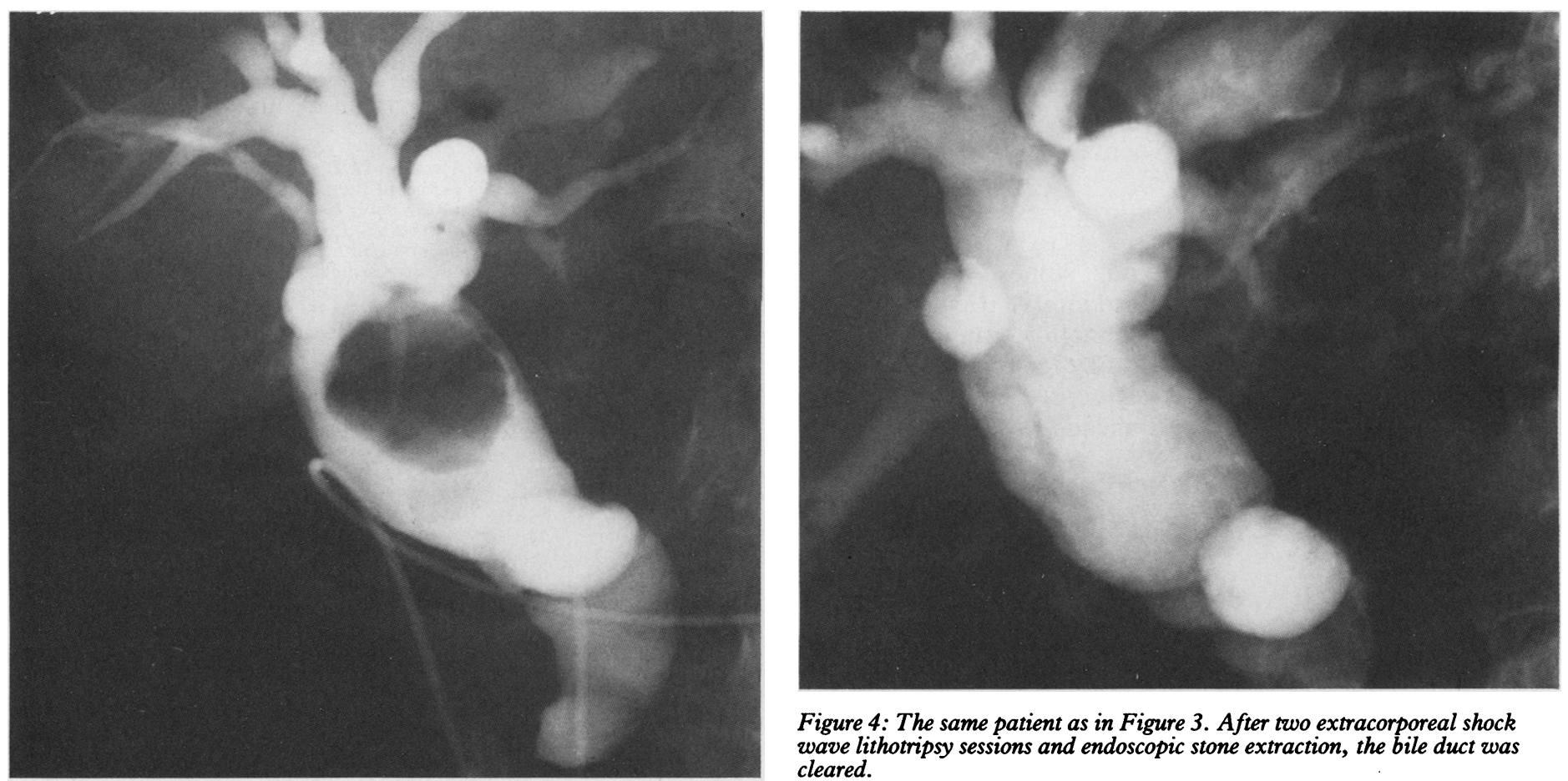

Figure 4: The same patient as in Figure 3. After two extracorporeal shock wave lithotripsy sessions and endoscopic stone extraction, the bile duct was cleared.

therapy and extracorporeal shock wave lithotripsy in bile duct stones. ${ }^{14}$

In the group of nine patients with intrahepatic stones, three could not be declared stone free; one was not amenable to radiological check up because of hypersensitivity to the contrast medium and the other two patients had undecisive endoscopic cholangiograms because of difficulty in differentiating air from small fragments in the ducts after spincterotomy. Ultrasound check up was of no value because of the same problem. All three patients, however, have been symptom free and have had normal liver tests during follow up at 15-38 months. If these are added to the group of evaluable patients, there is a $100 \%$ clinical success rate in the intrahepatic stone group.

Our results are in accordance with those of other centres..$^{22}{ }^{23}$ In the report by Bland et $a l^{10}$ the stone clearance rate was $74 \%$, but general anaesthesia was needed in $32 \%$ and regional block or infiltration anaesthesia in $29 \%$. This might reflect the disadvantage of treating few patients at multiple centres -42 patients at 11 centres in their series. In all our patients intravenous sedation and analgesia was sufficient and we achieved a higher rate of stone clearance, which may reflect an increased experience as a result of handling extracorporeal shock wave lithotripsy patients at a single institution. The Munich group, also using Dornier HM3 in a multicentre trial (113 patients - 12 centres), obtained stone clearance in $76 \%$ after one treatment session and in $86 \%$ after one or more additional sessions. ${ }^{24}$ General or peridural anaesthesia was used in $88 \%$ of the procedures. Hospital mortality was $1 \cdot 8 \%$ and the 30 day mortality $0.9 \%$. We had about the same stone clearance rate although general anaesthesia was not used and the mean age of our patients with common bile duct stones was considerably higher.
Shock waves are reported to induce soft tissue damage as a direct effect of the sonic pulsation or cavitation (the expansion and collapse of tiny air bubbles) with vascular damage and oedema on histologic examination. ${ }^{25}$ Although experimentally, changes have been found in the gut, liver, gall bladder and lung at biliary extracorporeal shock wave lithotripsy, coexisting biochemical abnormalities have not been reported. In a series of 311 patients routine liver tests (serum alkaline phosphatase, serum bilirubin, aspartate transaminase and serum amylase) pre and post extracorporeal shock wave lithotripsy for gall bladder stones did not produce complications. ${ }^{26}$ As the tests were deemed of little value, they were not routinely used for the urpose of monitoring effects of extracorporcas selock wave lithotripsy in our study.

Of all 41 patients referred for extracorporeal shock wave lithotripsy, three cases $(7 \%)$ had to be excluded for anatomical reasons; in one, severe kyphosis made targetting impossible, and in two with intrahepatic stones lung tissue was in the shock wave path. In another patient extracorporeal shock wave lithotripsy induced cardiac arrythmia after 600 shock waves at $15 \mathrm{kV}$, which is low energy, and the treatment was discontinued. This patient did not have a previous history of cardiac disease and recovered without any sequelae. The reason for the arrhythmia is unclear in this patient. There are few reports on cardiac arrythmia attributable to extracorporeal shock wave lithotripsy. ${ }^{27} \mathrm{We}$ did not try to retreat this patient with extracorporeal shock wave lithotripsy, who, however, received an endoscopic endoprosthesis. ${ }^{14}$ These problems limit the use of extracorporeal shock wave lithotripsy and have to be taken as failures of the technique. Perhaps the still newer technique of intraductal laser induced shock wave lithotripsy with the pulsed dye lasers or Alexandrite lasers has potential for overcoming these limitations of extracor- 
poreal shock wave lithotripsy or even replace it in the treatment of problematic bile duct stones. ${ }^{28}$ The laser induced shockwave lithotripsy unlike extracorporeal shock wave lithotripsy needs a direct contact of the energy source with the stone(s).

In summary, extracorporeal shock wave lithotripsy appears to be a safe and efficient treatment for bile duct stones. Thus, it is valuable adjunct to standard interventional techniques for removing problematic common and intrahepatic duct stones. It further extends the number of patients with bile duct stones, who can be treated by nonsurgical means.

1 Chaussy C, Schmiedt E, Jocham E, Brendel W, Forssman B, Walther W. First clinical experience with extracorporeally induced destruction of kidney stones by shock waves. $7 \mathrm{Urol}$ 1982; 127; 417-20.

2 Drach GW, Drethler S, Fair W, Finlayson B, Gillenwater J, Griffith D, et al. Report of the United States cooperative study of extracorporeal shock wave lithotripsy. F Urol 1986; 135: 1127-33.

3 Pettersson B, Tiselius HG. One year follow-up of an unselected group of renal stone formers treated with extracorporeal shock wave lithotripsy. F Endourology 1989; 3: 19_ 30 .

4 Sauerbruch T, Delius M, Paumgartner G, Holl J, Wess O, Weber W, et al. Fragmentation of gallstones by extracorporeal shock waves. $N$ Engl F Med 1986; 314: 818-22.

5 Sackmann M, Delius M, Sauerbruch T, Holl J, Weber W, Ippisch E, et al. Shock-wave lithotripsy of gallbladder stones: the first 175 patients. $N$ Engl $\mathcal{F}$ Med 1988; 318: stones:

6 Darzi A, Monson JRT, O'Morain C, Tanner WA, Keane FBV. Extension of selection criteria for extracorporeal shock wave lithotripsy for gall stones. $B M \mathcal{F} 1989 ; 298$ : 302-3.

7 Lacaine F. Extracorporeal lithotripsy of gallstones: a preliminary report. $\mathcal{F}$ Lithotripsy Stone Disease 1989; 1: 209-3.
, Biliary lithotripsy: Early observations in 106 patients. Radiology 1989; 171: 363-7.

9 Ross B, Johnsson A. Gallstone lithotripsy: the Sheffield experience. Scand F Urol Nephrol 1989; (suppl 122): 60-72.

10 Bland KI, Jones RS, Maher JW, Cotton PB, Pennell TC, Amerson JR, et al. Extracorporeal shock-wave lithotripsy of bile duct calculi. Ann Surg 1989; 209: 743-55.
11 Taylor MC, Marshall JC, Fried LA, LeBrun GP, Norman RW. Extracorporeal shock wave lithotripsy (ESWL) in the management of complex biliary tract tone disease. Ann Surg 1988; 208: 586-92

12 Becker CD, Fache JS, Gibney RG, Scudamore CH, Burhenne HJ. Choledocholithiasis: treatment with extracorporeal shock wave lithotripsy. Radiology 1987; 165: 407-8.

13 Classen M, Demling L. Endoskopische Sphinkterotomie der Papilla Vateri und Steinextraktion aus dem Choledochus. Dtsch Med Wochenschr 1974; 99: 496-7.

14 Cotton PB, Forbes A, Leung JWC, Dineen L. Endoscopic stenting for long treatment of large bile duct stones: 2- to 5-year follow-up. Gastrointest Endosc 1987; 33: 411-2.

15 Cotton PB. Endoscopic management of bile duct stones (apples and oranges). Gut 1984; 25 : 587-97.

16 Podolsky I, Kortan P, Haber GB. Endoscopic sphincterotomy in outpatients. Gastrointest Endosc 1989; 35: 372-6.

17 Schmack B. Dissolution of bile duct stones. Endoscopy 1983 ; 15: 186-90.

18 Thistle LJ. Direct contact dissolution of gallstones. Semin Liver Dis 1987; 88: 311-6.

19 Carr-Locke DL, Cotton PB. Biliary tract and pancreas. $\mathrm{Br} \mathrm{Med}$ Bull 1986; 42: 257-64.

20 Sheridan WG, Williams HOL, Lewis MH. Morbidity and mortality of common bile duct exploration. BrF Surg 1987; 74: 1095-9.

21 McSherry GK, Glenn F. The incidence and causes of death following surgery for non-malignant biliary tract disease. following surgery for non-mati

22 Lee SH, Fache J, Burhenne J. The value of extracorporeal shockwave lithotripsy in the management of bile duct stones. Third International Symposium Biliary Lithotripsy (Abstract), Sept 13-15, Munich, Germany.

23 Ginestal-Cruz A, Grima N, Duarte V, Correia AP, Tavora I. Extracorporeal shock wave lithotripsy for large common bile duct stones: an extension of the endoscopic approach. f Lithotripsy Stone Disease 1989; 1: 272-81.

24 Sauerbruch T, Stern M. Fragmentation of bile duct stones by extracor

25 Delius M. Brendel W. Mechanism of action in extracorporeal shock wave lithotripsy: experimental studies. In: Ferrucci JT, Delius M, Burhenne HJ, eds. Biliary lithotripsy. J , Delius M, Burhenne HJ, eds. B

26 Goodacre BW, Malone DE, Fache JS, Rawat B. Burhenne HJ. Routine liver function tests and serum amylase determinations after biliary lithotripsy: Are they necessary? $A \mathcal{F} R$ 1990; 155: 771-4.

27 Rambow A, Staritz M, Grosse A, Treese N, Meyer zum Büschenfelde K-H. Extrasystolia during electromagnetically biliary extracorporeal shock wave lithotripsy: incidence and clinical relevance. Third International Symposium Biliary Lithotripsy (Abstract), September 13-15, 1990 Munich, Germany.

28 Cotton PB, Kozarek R, Shapiro RH, Nishioka NS, Kelsey PB, Ball TJ, et al. Endoscopic laser lithotripsy of large bile duct stones. Gastroenterology 1990; 99: 1128-33. 